Article

\title{
Novel Application Research on Critical High-Temperature Deformation of Low-Lead Brass Alloy
}

\author{
Kuan-Jen Chen \\ Instrument Center, Instrument Development Center, National Cheng Kung University, Tainan 701, Taiwan; \\ kjchen1982@gmail.com; Tel.: +886-6-2757-575-31377; Fax: +886-6-2373-476 \\ Received: 17 April 2020; Accepted: 26 May 2020; Published: 28 May 2020

\begin{abstract}
This study investigated the critical high-temperature deformation of the low-lead $(\mathrm{Pb})$ $\mathrm{Cu} 38 \mathrm{Zn} 3 \mathrm{~Pb}$ alloy. Moreover, the dezincification mechanism of this alloy for high-temperature applications was evaluated. The results reveal that tensile temperatures influence the phase structures of the brass alloy matrix. Many voids and holes formed at the phase boundaries above $400{ }^{\circ} \mathrm{C}$ due to the hard-brittle $\beta^{\prime}$ phase which transformed into the softer $\beta$ phase, thus causing low-strength and high-ductility values. High strain rate deformation promotes more obvious intermediate-temperature brittleness in the brass alloy. The $\mathrm{Cu} 38 \mathrm{Zn} 3 \mathrm{~Pb}$ alloys display the lowest impact toughness between $400{ }^{\circ} \mathrm{C}$ and $600{ }^{\circ} \mathrm{C}$. Long-term hot working caused dezincification in the brass alloy, thus deteriorating its ductility. The influences of thermal dezincification on the mechanical properties of the alloy must be considered during processing or heat treatment.
\end{abstract}

Keywords: high-temperature deformation; $\mathrm{Cu}-\mathrm{Zn}-\mathrm{Pb}$ alloy; dezincification; intermediate-temperature brittleness

\section{Introduction}

Brass alloys are composed of copper $(\mathrm{Cu})$ and zinc $(\mathrm{Zn})$, which form a substitutional alloy. The strength and wear resistance of the alloys can be improved through the use of a solid solution of $\mathrm{Zn}$ in $\mathrm{Cu}$. According to a previous report [1], the tensile strength of brass generally increased with an increase in $\mathrm{Zn}$ content when the $\mathrm{Zn}$ content was less than $45 \mathrm{wt} . \%$; while the $\mathrm{Zn}$ content in the brass exceeded $45 \mathrm{wt} . \%$, and its strength deteriorated rapidly. The most used brass in industrial application contains a $\mathrm{Zn}$ content of 30-45 wt.\% [2,3], and its performance can be improved through adding alloy elements ( $\mathrm{Al}, \mathrm{Sn}, \mathrm{Ni}, \mathrm{Fe}$ ) [4-6]. To improve the applicability of free-cutting brass, this study reduces lead $(\mathrm{Pb})$ content and adds $\mathrm{Fe}$ and $\mathrm{Sn}$ to fabricate the $\mathrm{Cu}-38 \mathrm{Zn}-3 \mathrm{~Pb}(\mathrm{Cu} 38 \mathrm{Zn} 3 \mathrm{~Pb})$ alloy and evaluate its thermal resistance.

Brass with less than $45 \mathrm{wt} . \% \mathrm{Zn}$ is usually used in industrial applications. It can be divided into $\alpha$ brass, $\alpha+\beta^{\prime}$ brass, and $\beta^{\prime}$ brass, and their microstructures are influenced by $Z n$ content. The strength of $\alpha$ brass after a solution treatment is higher than that of pure $\mathrm{Cu}$, and has excellent ductility at room temperature; the texture of $\beta^{\prime}$ brass is hard, but its toughness is poor. Therefore, $\alpha+\beta^{\prime}$ brass can undergo a larger load than $\alpha$ brass, and its applications are wider. Moreover, the high-temperature $\beta$ phase is softer than the low-temperature $\beta^{\prime}$ phase, which causes $\alpha+\beta^{\prime}$ brass to have a better hot workability [7]. In recent years, lead-free or low-lead free-cutting brasses have been investigated, among which $\mathrm{Cu}-\mathrm{Zn}-\mathrm{Si}$ and $\mathrm{Cu}-\mathrm{Zn}-\mathrm{Bi}$ alloys are mainly used [8,9]. However, the cost of lead-free or low-lead free-cutting brass is high, and its high-temperature strength remains to be improved. Therefore, $\alpha+\beta^{\prime}$ brass with $38-40 \mathrm{wt} . \% \mathrm{Zn}$, a low content of $1-2 \mathrm{wt} . \% \mathrm{~Pb}$ and traces of $\mathrm{Fe}$ and $\mathrm{Sn}$ 
was used in this study, which explores the influences of hot working conditions on the mechanical properties of brass.

Metals are subjected to high-temperature plastic processing, which causes dynamic recovery and dynamic recrystallization to occur $[10,11] . \mathrm{Cu}$ is a low stacking fault energy metal, thus indicating a low dynamic recovery and obvious dynamic recrystallization under high-temperature strain [12]. The addition of $\mathrm{Zn}$ to the brass used in the present study will reduce the stacking fault energy and dynamic recovery, causing obvious dynamic recrystallization to improve high-temperature formability [13]. In general, the displacement of dislocation in metals is easier with an increase in temperature, causing an easier deformation and a high ductility. However, an intermediate-temperature brittleness phenomenon was found in $\mathrm{Cu}$ alloys [14]. The dual-phase brass (40 wt.\% Zn) has a higher tensile strength than the single-phase brass (30 wt.\% $\mathrm{Zn}$ ) at room temperature. The strength and toughness of both brass alloys decreased significantly when the temperature exceeded $400{ }^{\circ} \mathrm{C}$. However, the impact toughness of the dual-phase brass recovered when the temperature was increased to $500{ }^{\circ} \mathrm{C}$ [15]. For the brass with a Pb content above $1 \mathrm{wt} . \%$, intermediate-temperature brittleness appeared significantly at low temperatures due to softened $\mathrm{Pb}$, which resulted in a decrease in the strength of the grain boundary [16]. The processing technology for brass that can be directly hot-worked at high temperatures is novel. Therefore, this study conducts a high-temperature impact test, as clarifying the effect of intermediate-temperature brittleness on brass is important for academic research. Moreover, $\mathrm{Zn}$ atoms in brass will be released under long-term hot working, which influence the mechanical properties of the material [17]. Notably, the critical conditions and diffusion mechanisms of the dezincification in brass have not yet been clarified.

Therefore, in this study, the low-Pb dual-phase brass alloy was fabricated, and the effects of various temperatures and strain rates on the mechanical properties of the alloy were explored. Moreover, the influences of hot working conditions on the fracture mechanism and the dezincification of the brass alloy were investigated. The results can also be used as a data base for practical applications.

\section{Materials and Methods}

A hot extruded low-lead Cu38Zn3Pb alloy $\left(\alpha+\beta^{\prime}\right.$ phase brass) rod (JIN JIA SING Industry Corporation, Taoyuan, Taiwan) was used in the present study, and the chemical composition is presented in Table 1. The tensile and impact specimens fabricated using the alloy rods were shaped, and the dimensions of these specimens are displayed in Figure 1. Tensile and impact tests were used to evaluate the influences of various temperatures on the deformation resistance and impact toughness of the given alloy specimens. The tensile temperatures were configured at $25-600{ }^{\circ} \mathrm{C}$ for $10 \mathrm{~min}$ to conduct tensile tests with an initial strain rate set of $1.67 \times 10^{-3} \mathrm{~s}^{-1}$ by a universal material tester (Hung Ta Instrument Corporation, Taichung, Taiwan). For the impact toughness, the given specimens were heated at $25-750{ }^{\circ} \mathrm{C}$ for $10 \mathrm{~min}$ using the Charpy impact test. A pendulum with a weight of $25 \mathrm{~kg}$, a length of $0.75 \mathrm{~m}$, and an initial angle of $120^{\circ}$ was used for the impact test. An impact angle was obtained after the impact test, and the impact energy corresponding to each temperature was calculated. Moreover, the dezincification test was configured at $700{ }^{\circ} \mathrm{C}$ for $1 \mathrm{~h}$ and $12 \mathrm{~h}$ to explore the phenomenon of zinc release, and the effects of dezincification on the mechanical properties of the $\mathrm{Cu} 38 \mathrm{Zn} 3 \mathrm{~Pb}$ alloy specimen.

Table 1. Chemical composition of Cu-38Zn-3Pb alloy (wt.\%).

\begin{tabular}{ccccccc}
\hline Element & $\mathbf{Z n}$ & $\mathbf{P b}$ & $\mathbf{F e}$ & $\mathrm{Sn}$ & $\mathbf{N i}$ & $\mathbf{C u}$ \\
\hline wt. $\%$ & 38.10 & 3.30 & 0.22 & 0.21 & 0.12 & Bal. \\
\hline
\end{tabular}




\section{Tensile test specimen}

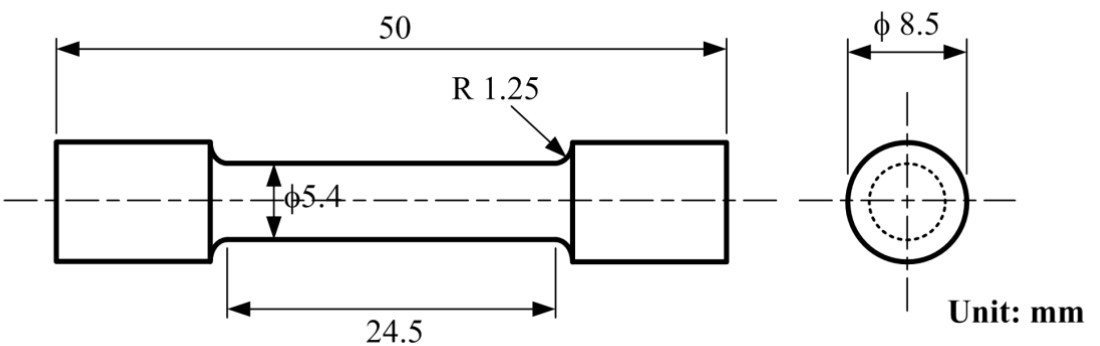

\section{Impact test specimen}
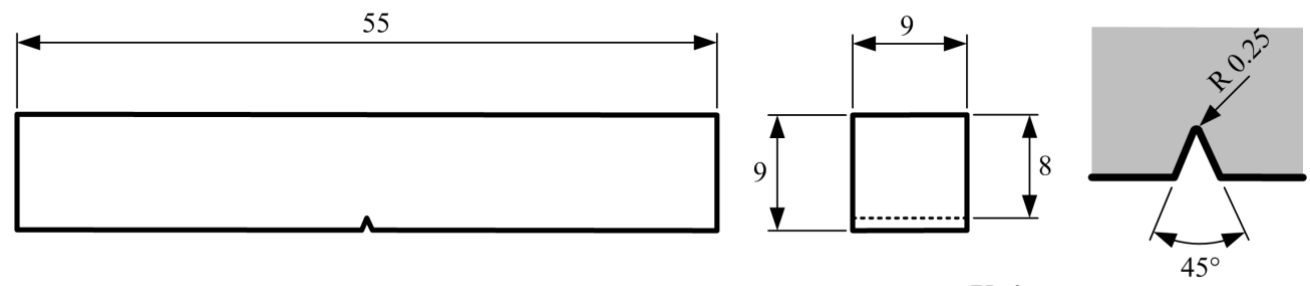

Unit: $\mathbf{m m}$

Figure 1. Dimensions of tensile and impact specimens.

The following steps were conducted to investigate the effects of high-temperature tensile and impact tests on microstructural evolution: The alloy specimens were polished using up to \#4000-grit SiC papers, and etched through 2 wt.\% $\mathrm{FeCl}_{3}$ ethanol solution. Then, the microstructural morphologies of the resulting specimens were observed through optical microscopy (OM) (OLYMPUS, Tokyo, Japan). After the tensile and impact tests, the fracture surface and subsurface morphologies of the specimens were observed using scanning electron microscopy (SEM) (HITACHI, Tokyo, Japan) to clarify the mechanism of fracture. The phase composition of the dezincification of the specimen surface was examined using an X-ray diffractometer (XRD) (Bruker, Madison, WI, USA). Moreover, the given alloy specimen was examined by secondary ion mass spectroscopy (SIMS) using a CAMECA IMS-7f analyzer (CAMECA, Genevilliers, France) with an $\mathrm{O}_{2}$ primary ion beam to examine the effect of long duration heating on dezincification.

\section{Results and Discussion}

\subsection{Influence of Temperature on Plastic Deformation}

A macrograph image of the low-lead $\mathrm{Cu} 38 \mathrm{Zn} 3 \mathrm{~Pb}$ alloy rod is displayed in Figure 2a. The material used for the present study corresponds to a high-Zn content $\mathrm{Cu} 38 \mathrm{Zn} 3 \mathrm{~Pb}$ alloy. At room temperature, two main phases appear in the alloy specimen along the extrusion direction (ED) plane; these phases correspond to the $\alpha$ and $\beta^{\prime}$ phases, respectively; see Figure $2 \mathrm{~b}$. The trace amount of Pb was not solidified in the alloy matrix and was distributed at the boundaries between the $\alpha$ and $\beta^{\prime}$ phases. The present $\mathrm{Cu} 38 \mathrm{Zn} 3 \mathrm{~Pb}$ alloy corresponds to $\alpha+\beta^{\prime}$ brass [7], which causes the alloy to have a better hot workability. However, the $\beta$ phase in the alloy matrix is transferred into the $\beta^{\prime}$ phase during the hot working process [18]. Furthermore, the liquid $\mathrm{Pb}$ phase penetrated the phase boundaries, thus influencing the mechanical properties of material. Based on the aforementioned results, it is necessary to clarify the influences of hot working conditions on the processing characteristics of $\alpha+\beta^{\prime}$ brass. 


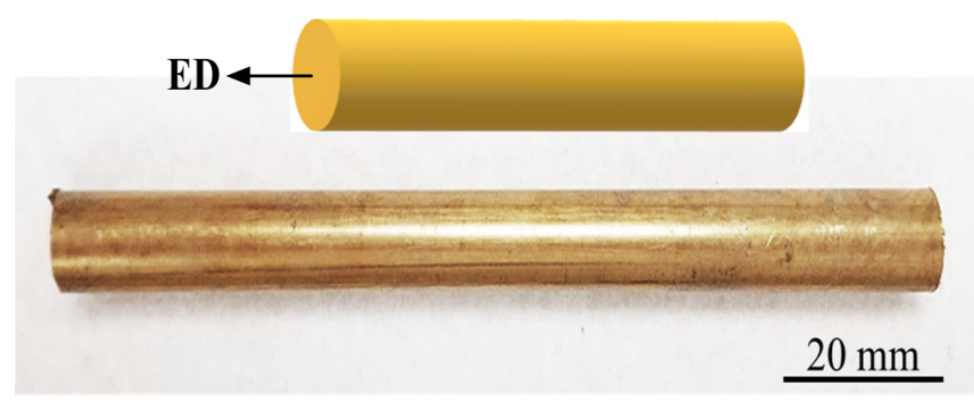

(a)

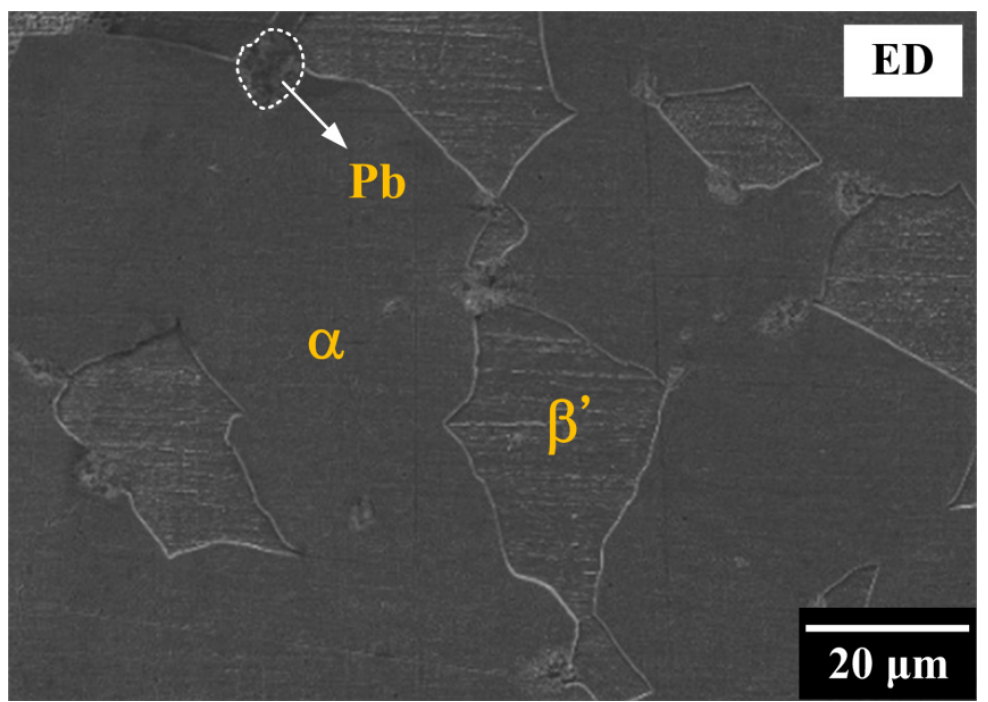

(b)

Figure 2. Cu38Zn3Pb alloy: (a) Macrograph, (b) Microstructure images.

The deformation resistances of the $\mathrm{Cu} 38 \mathrm{Zn} 3 \mathrm{~Pb}$ alloy specimen at different temperatures were determined through the tensile test displayed in Figure 3. The stress-strain curves obtained from the tensile specimens of the given alloy subjected to a tensile test at $25{ }^{\circ} \mathrm{C}$ to $600{ }^{\circ} \mathrm{C}$ are displayed in Figure $3 \mathrm{a}$. The results revealed that the tensile strengths of the given specimens at $25^{\circ} \mathrm{C}$ to $300{ }^{\circ} \mathrm{C}$ were higher than $500 \mathrm{MPa}$, and the ductility did not significantly change; see Figure $3 \mathrm{~b}, \mathrm{c}$. The tensile strength of the specimen decreased substantially with an increase in temperature, and its ductility increased. The plastic deformation exhibits a total elongation of more than $20 \%$, but the uniform elongation decreased. This finding revealed that the alloy used in the present study showed a weakened high-temperature tensile strength, and had a brittle behavior of low uniform deformation. In this case, the test result is not consistent with the literature that reported the brittle behavior of reduced elongation at intermediate-temperature [19]. The deformation resistance of the given alloy at intermediate-temperature needs further investigation to clarify the material deformation characteristics.

The fracture surface and subsurface morphologies of the specimens after the tensile test were examined to analyze the tensile fracture behavior of the $\mathrm{Cu} 38 \mathrm{Zn} 3 \mathrm{~Pb}$ alloy at different temperatures; see Figure 4 . Many dimples formed on the fracture surface at room temperature $\left(25^{\circ} \mathrm{C}\right)$. The dimple structures decreased and the proportion of cleavages increased with an increase in temperature, thus indicating that the fracture behavior tended to show brittle failure. At temperatures of $500{ }^{\circ} \mathrm{C}$ and $600{ }^{\circ} \mathrm{C}$, the fracture surface still showed brittle fracture morphology. This indicates that the $\mathrm{Cu} 38 \mathrm{Zn} 3 \mathrm{~Pb}$ alloy has high-temperature brittle failure behavior. Subsurface observations of the tensile specimens below $300{ }^{\circ} \mathrm{C}$ reveal that a material fracture did not proceed along a specific interface, but occurred in the $\alpha$ or $\beta^{\prime}$ phase, which is a transgranular fracture. For the $400{ }^{\circ} \mathrm{C}$ tensile specimen, the $\alpha$ phase is round and its boundary is complete, which indicates that the fracture tended to occur at the phase boundaries and in the $\beta^{\prime}$ phase. 
Many voids and holes can be found at the phase boundary, which is attributed to a sliding between the $\alpha$ and $\beta^{\prime}$ phases [20]. In an environment above $400{ }^{\circ} \mathrm{C}$, the ductility of the specimens increased due to an increase in temperature which deteriorated the phase boundary strength. Moreover, the hard and brittle $\beta^{\prime}$ phase transformed into the softer $\beta$ phase at high temperatures $\left(>400^{\circ} \mathrm{C}\right)$, thus decreasing the strength and improving the ductility.

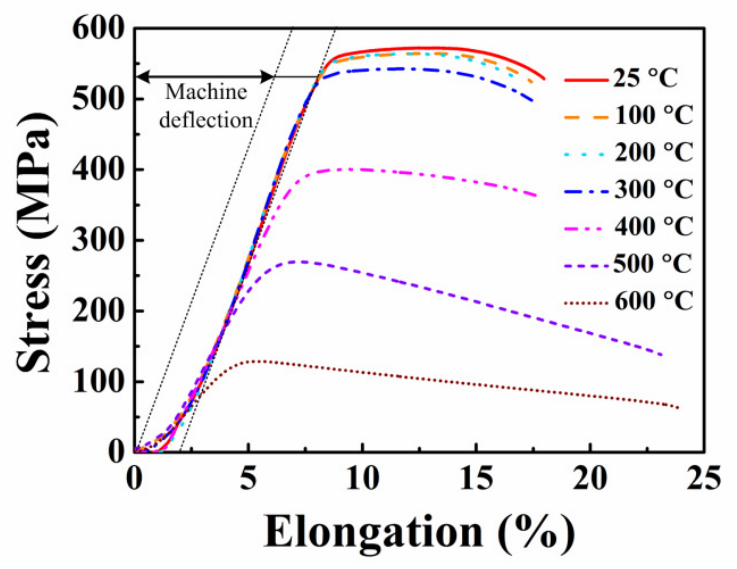

(a)

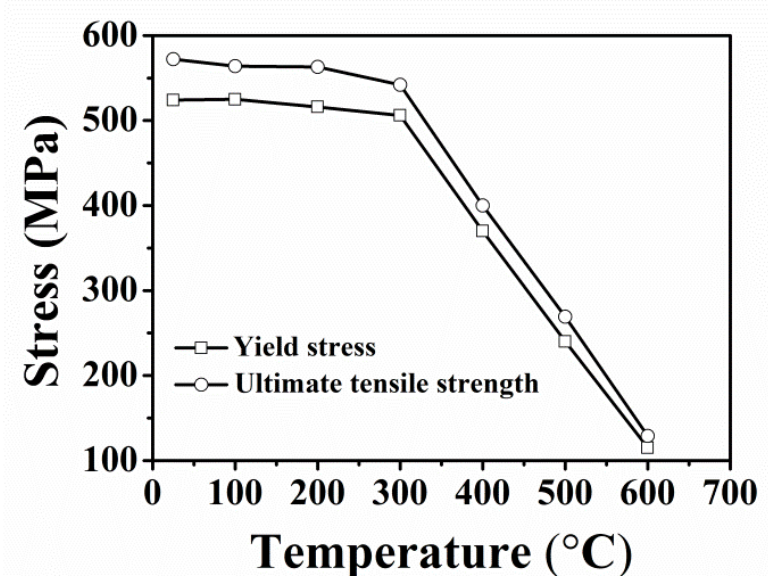

(b)

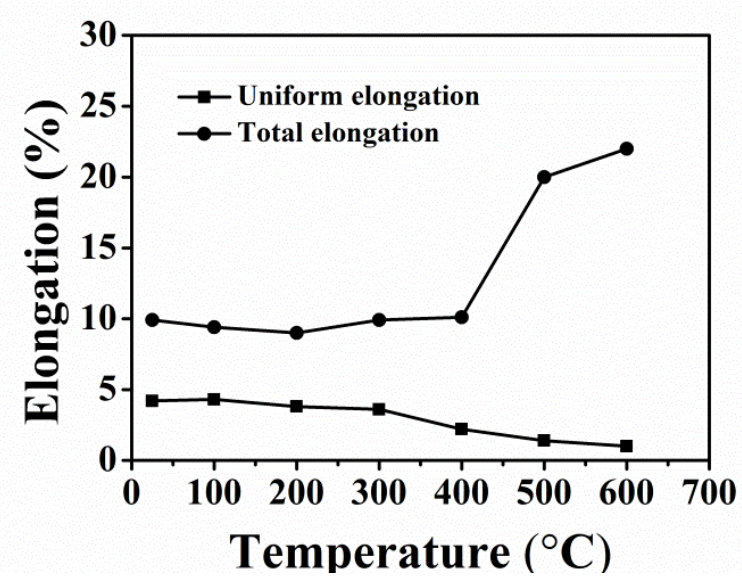

(c)

Figure 3. Tensile properties of $\mathrm{Cu} 38 \mathrm{Zn} 3 \mathrm{~Pb}$ alloy from room temperature to high temperature: (a) Stress-strain curve, (b) Tensile strength, (c) Elongation. 

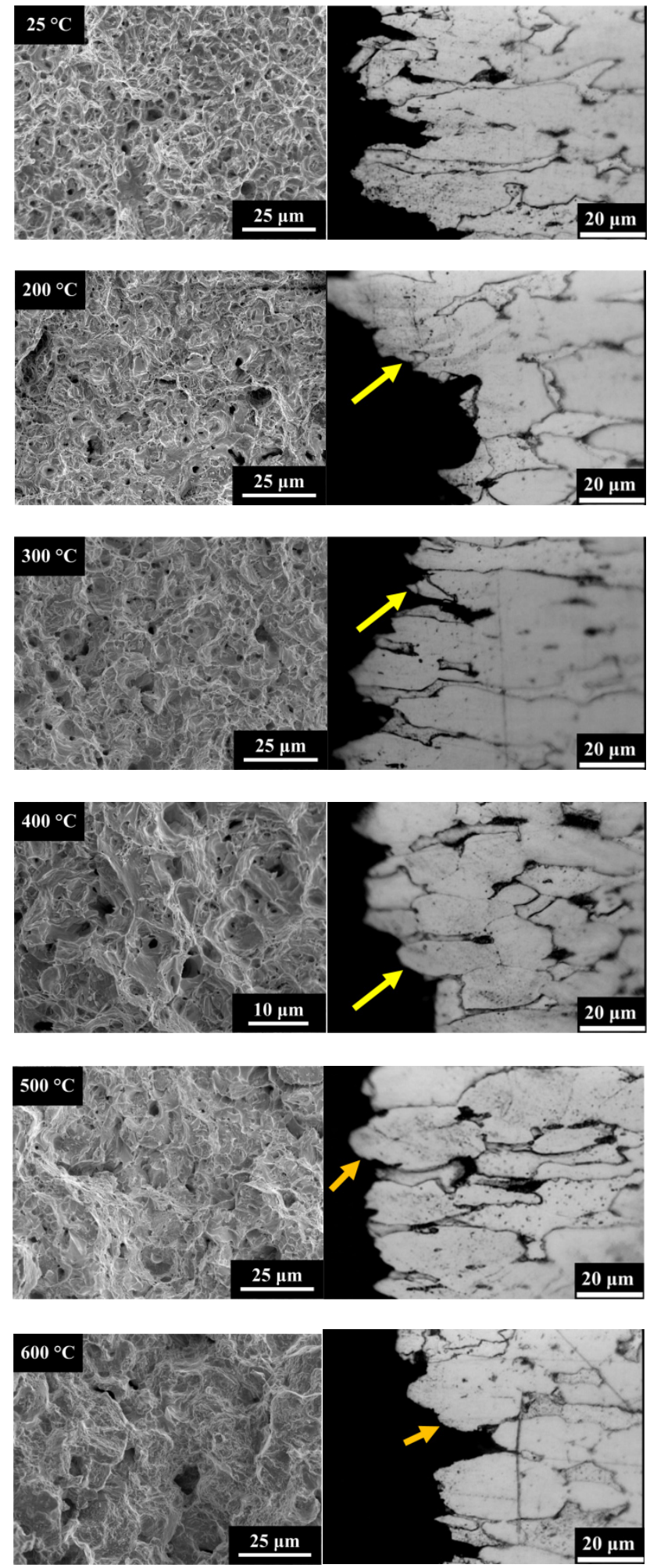

Figure 4. Fracture surface and subsurface morphologies of $\mathrm{Cu} 38 \mathrm{Zn} 3 \mathrm{~Pb}$ alloy specimens after tensile test at different temperatures.

Tensile tests of $500{ }^{\circ} \mathrm{C}$ with higher strain rates $\left(1.67 \times 10^{-1} \mathrm{~s}^{-1}\right.$ and $\left.1.67 \times 10^{-2} \mathrm{~s}^{-1}\right)$ were performed to understand the plastic deformation and rheological properties of the $\mathrm{Cu}-\mathrm{Zn}-\mathrm{Pb}$ alloy at high temperatures. The tensile strength of the $\mathrm{Cu} 38 \mathrm{Zn} 3 \mathrm{~Pb}$ specimens increased, and their ductility decreased with an increase in the strain rate; see Figure 5. Subsurface observation of the tensile 
specimen with a low strain rate reveals that many gaps and holes were observed at the grain boundaries, indicating an obvious sliding phenomenon. More cleavage in the phase was observed during high strain rate deformation. Tensile toughness of the alloy specimens can be obtained through calculating the integrated area under the stress-strain curve. The toughness is higher at a low strain rate, indicating that the formation of voids and holes can help energy absorption during fracture. Grain boundary sliding accompanied atomic diffusion; thus, the low strain rate allowed the atoms to sufficiently diffuse, resulting in the formation of gaps and holes in the grain boundaries, which provides the required ductility during deformation. This is the main deformation mechanism at high temperatures. Therefore, the subsurface morphology of the tensile specimen with a high strain rate exhibits low ductility.

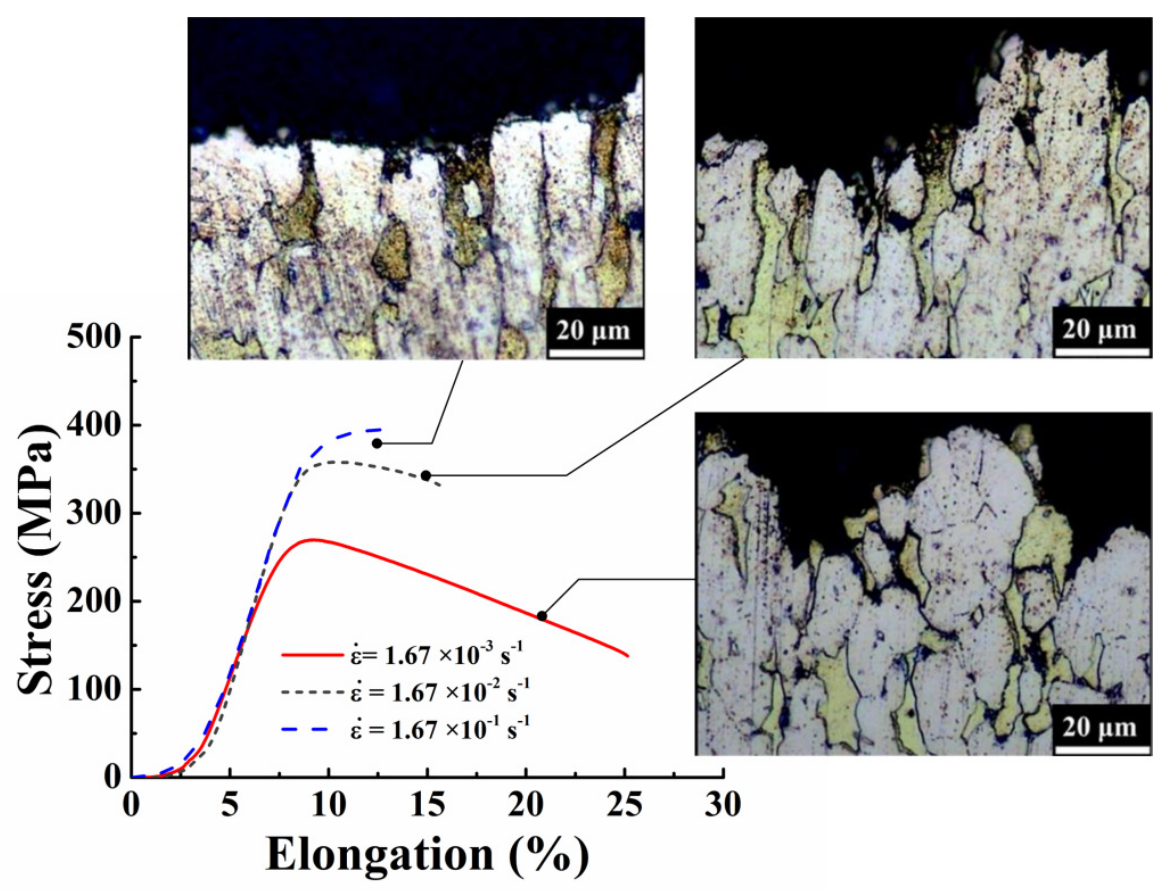

Figure 5. Stress-strain curves as a function of subsurface morphologies for $\mathrm{Cu} 38 \mathrm{Zn} 3 \mathrm{~Pb}$ alloy specimens.

\subsection{High-Strain and High-Temperature Plastic Deformation Characteristics}

Figure 6 displays the impact toughness as a function of the test temperatures pertaining to the given alloy specimens. The impact toughness of the alloy specimen at room temperature was similar to that of $200^{\circ} \mathrm{C}$. The impact toughness of the specimens gradually decreased with an increase in temperature, and reached their minimum values in the range of $400-600{ }^{\circ} \mathrm{C}$. Then, the impact toughness value started to increase when the test temperature exceeded $600^{\circ} \mathrm{C}$. This finding confirmed that the impact brittleness of the $\mathrm{Cu} 38 \mathrm{Zn} 3 \mathrm{~Pb}$ alloy existed between $400{ }^{\circ} \mathrm{C}$ and $600{ }^{\circ} \mathrm{C}$.

Fracture surface and subsurface observations of the given alloy specimen obtained after the impact test are displayed in Figure 7. The results observed that the fracture mechanism of the alloy specimen below $400{ }^{\circ} \mathrm{C}$ corresponded to the transgranular failure due to a low relative temperature and high strain rate. The existence of voids and holes can be observed at $600^{\circ} \mathrm{C}$, and the cracks extend from the grain boundary. This indicates that the deformation of the alloy has a phase boundary sliding phenomenon. The fracture morphologies of the specimens were transformed into transgranular failure again at temperatures above $700{ }^{\circ} \mathrm{C}$. Moreover, many fine particles were present on the formed boundaries, and energy dispersive spectroscopy (EDS) (HITACHI, Tokyo, Japan) analysis confirmed that these fine structures were $\mathrm{Pb}$ particles; see Figure 8. The voids existed between the grain boundaries. This result reveals that the $\mathrm{Pb}$ existing in the voids melted at high temperatures, thus causing molten $\mathrm{Pb}$ to penetrate the grain boundaries, which resulted in a decrease in phase boundary strength. This indicates that the intermediate-temperature 
brittleness of the given alloy has a specific temperature range, and the brittleness behavior becomes more obvious with an increase in the strain rate.

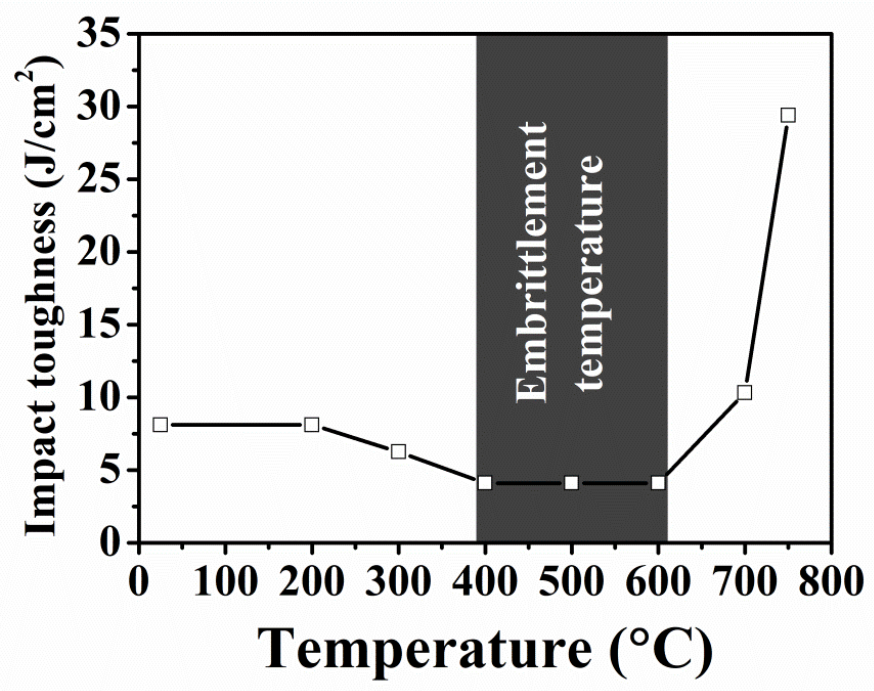

Figure 6. Impact toughness as a function of test temperatures for $\mathrm{Cu} 38 \mathrm{Zn} 3 \mathrm{~Pb}$ alloy specimens.
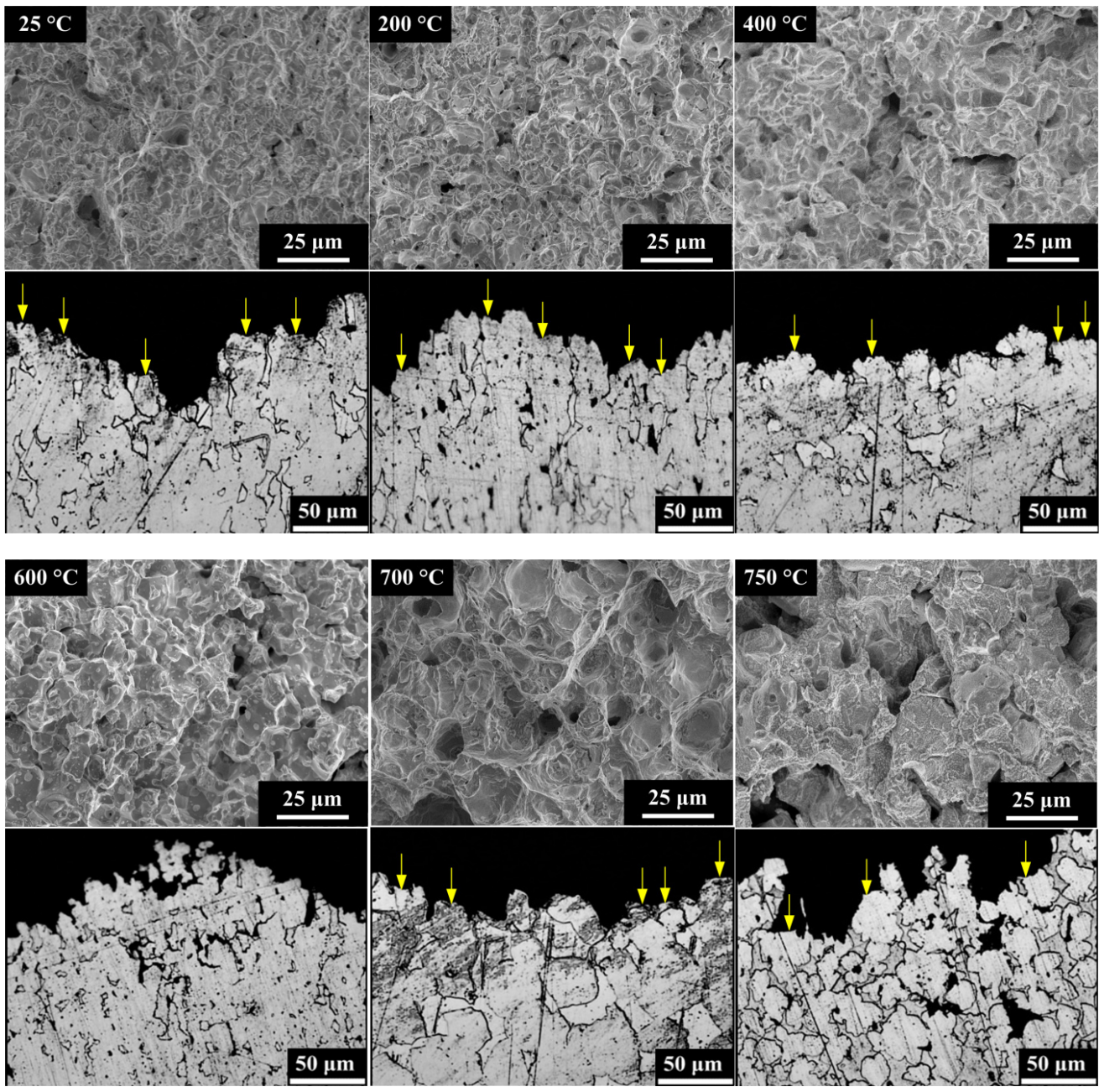

Figure 7. Fracture surface and subsurface morphologies of $\mathrm{Cu} 38 \mathrm{Zn} 3 \mathrm{~Pb}$ alloy specimens obtained after impact test at different temperatures. 


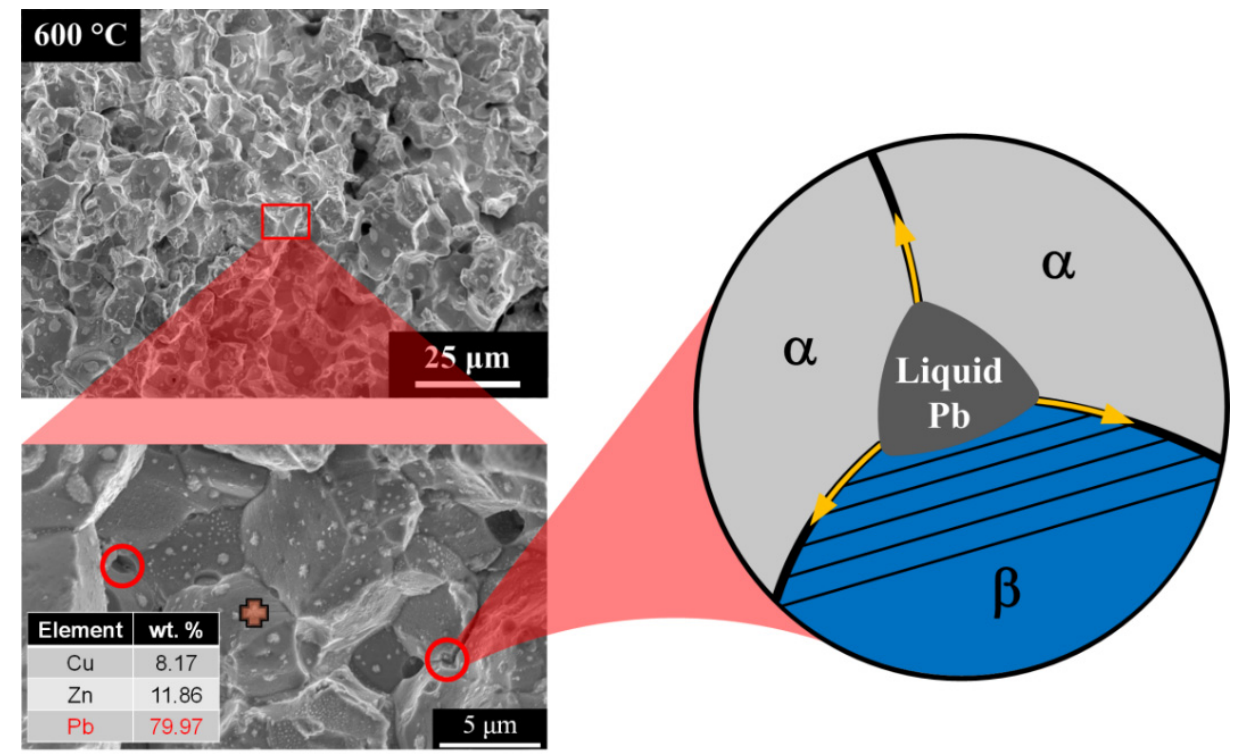

Figure 8. Impact fracture surface and EDS analysis of $\mathrm{Cu} 38 \mathrm{Zn} 3 \mathrm{~Pb}$ alloy specimen at $600{ }^{\circ} \mathrm{C}$.

\subsection{Mechanism of High-Temperature Dezincification}

According to a previous report [21], $\mathrm{Zn}$ in the $\mathrm{Cu}-\mathrm{Zn}$ alloy easily escaped at high temperatures due to its high vapor pressure, which reduced the $\mathrm{Zn}$ content in the material and thus influenced its structure. In addition, the dezincification behavior of brass occurred easily in a high Zn content $\beta$ solid solution, which diffused outward from the grain boundaries, causing a loose $\mathrm{Cu}$-rich layer, and thus decreased the mechanical properties of the alloy [16]. The macrograph images of the tensile $\mathrm{Cu} 38 \mathrm{Zn} 3 \mathrm{~Pb}$ specimens obtained after high-temperature heat treatment are displayed in Figure $9 \mathrm{a}$. The surface of the 12-h-heated specimen displays an obvious film peeling. This finding confirmed that the composition of the peeled film was $\mathrm{ZnO}$, indicating that the alloy specimen had been severely dezincified. Moreover, $\mathrm{Cu}, \mathrm{Zn}$, and $\mathrm{Pb}$ contents of the alloy specimen surface where the $\mathrm{ZnO}$ film had peeled off were detected using SIMS to clarify the influence of dezincification on structural characteristics; see Figure $9 \mathrm{~b}$. The $\mathrm{Zn}$ content pertaining to the surface of the 12-h-heated specimen is slightly higher than that pertaining to the surface of the given specimen. This finding can be attributed to a residual $\mathrm{ZnO}$ film that was detected on the specimen surface. The $\mathrm{Cu}$ content of the 12-h-heated specimen surface is lower than that of the given specimen surface, but the $\mathrm{Pb}$ content is higher. The dezincification behavior caused a large amount of $\mathrm{Zn}$ to diffuse towards the specimen surface. This result caused the precipitation of $\mathrm{Pb}$ which accumulated on the specimen surface where the $\mathrm{ZnO}$ film had peeled off, and thus the $\mathrm{Cu}$ migrated towards the alloy matrix; see Figure 9c.

The mechanical properties of the 1-h and 12-h-heated specimens were also determined through the tensile test; see Figure 10. The tensile strength of the 12-h-heated specimen is slightly lower than that of the 1-h-heated one, and the elongation is approximately $19 \%$ lower. This indicates that long-term high-temperature exposure increases dezincification, causing the accumulation of high-content $\mathrm{Pb}$ on the specimen surface, which results in the deterioration of the mechanical properties of the specimen. To summarize, for the processing and heat treatment of the $\mathrm{Cu}-\mathrm{Zn}$ alloy, the influences of thermal dezincification on its mechanical properties must be considered. 


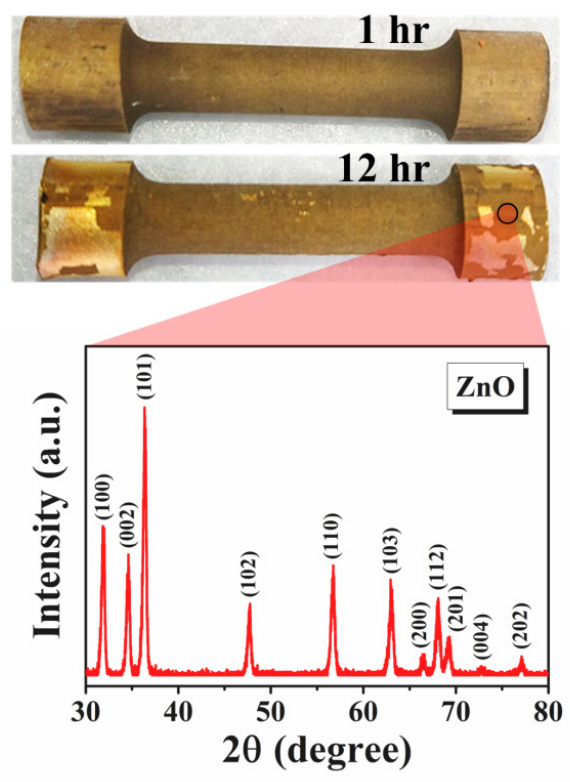

(a)
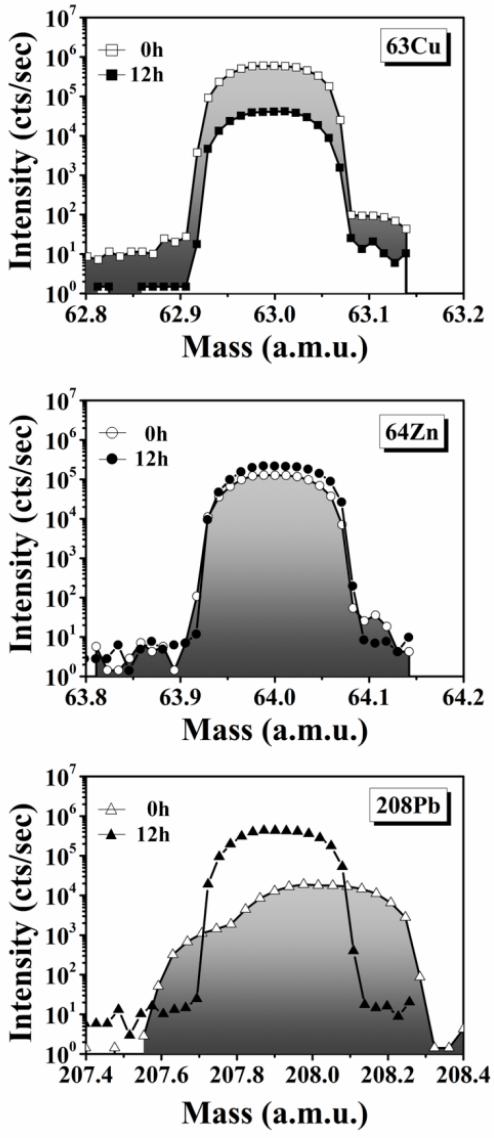

(b)

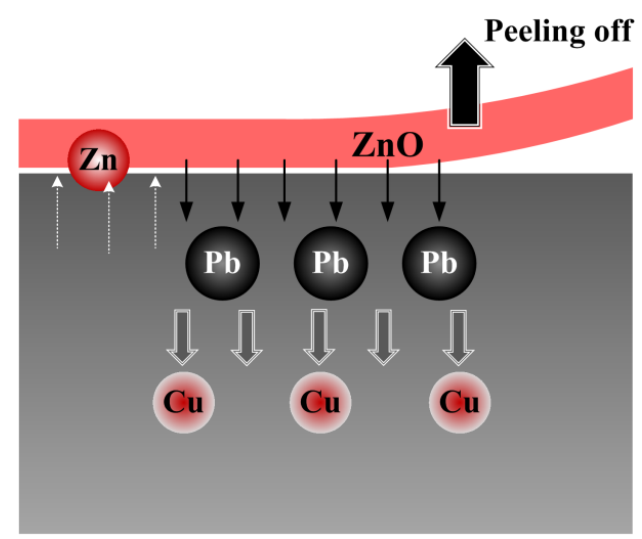

(c)

Figure 9. $\mathrm{Cu} 38 \mathrm{Zn} 3 \mathrm{~Pb}$ alloy specimens after dezincification test: (a) Surface observations and X-ray diffractometer, (b) High-resolution mass analyses, (c) Dezincification mechanism of Cu38Zn3Pb alloy after long-term hot working. 


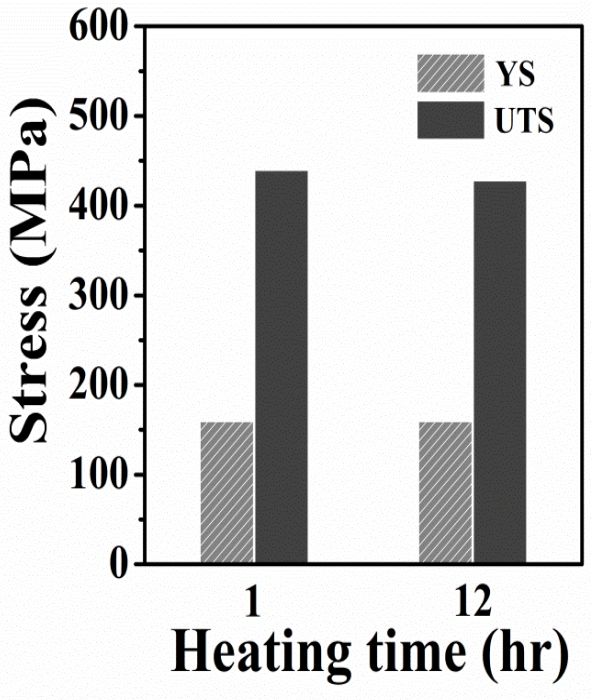

(a)

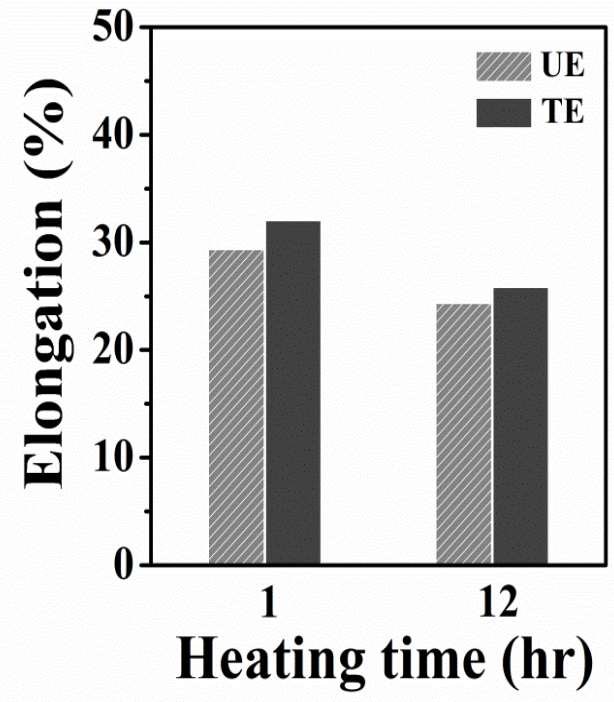

(b)

Figure 10. Tensile properties as a function of heating duration for $\mathrm{Cu} 38 \mathrm{Zn} 3 \mathrm{~Pb}$ alloy specimens; (a) Tensile strength, (b) Elongation.

\section{Conclusions}

The mechanical properties and fracture mechanisms of the $\alpha+\beta^{\prime}$ phase brass alloy after high-temperature tensile and impact tests were investigated in this study. The tensile strength of the alloy decreased as the tensile temperature was increased, and its ductility increased. High temperatures $\left(>400{ }^{\circ} \mathrm{C}\right.$ ) led to a sliding grain boundary and reduced the grain boundary strength. Moreover, the $\beta^{\prime}$ phase was transformed into a high-ductility $\beta$ phase when the temperature exceeded $400{ }^{\circ} \mathrm{C}$, which greatly improved ductility. The impact test confirmed that the $\mathrm{Cu} 38 \mathrm{Zn} 3 \mathrm{~Pb}$ alloy demonstrates an intermediate-temperature brittleness phenomenon in the range of $400-600{ }^{\circ} \mathrm{C}$. A high strain rate led to more obvious brittleness behavior of the alloy. A large amount of $\mathrm{Zn}$ was released from the alloy after a long-term high-temperature heat treatment, resulting in the formation of a $\mathrm{ZnO}$ film on the specimen surface. The precipitation of a $\mathrm{Pb}$ layer obtained after the dezincification caused the $\mathrm{Cu} 38 \mathrm{Zn} 3 \mathrm{~Pb}$ alloy specimen to exhibit less elongation.

Funding: This research received no external funding.

Acknowledgments: The authors are grateful to the Ministry of Science and Technology, Taiwan, Instrument Center at National Cheng Kung University (NCKU), the Department of Materials Science and Engineering of NCKU, and the Institute of Microelectronics and the Department of Electrical Engineering of NCKU for supporting this study.

Conflicts of Interest: The authors declare no conflict of interest.

\section{References}

1. Reed-Hill, R.E.; Abbaschian, R. Physical Metallurgy Principles, 3rd ed.; PWS-KENT: Boston, MA, USA, 1992; pp. 691-692.

2. Zaretsky, E.B.; Kanel, G.I. Abnormal temperature effects on the dynamic yield stress of alpha-brass. J. Appl. Phys. 2018, 124, 045902. [CrossRef]

3. Davoodi, A.; Honarbakhsh, S.; Farzi, G.A. Evaluation of corrosion resistance of polypyrrole/functionalized multi-walled carbon nanotubes composite coating on 60Cu-40Zn brass alloy. Prog. Org. Coat. 2015, 88, 106-115. [CrossRef]

4. Adineh, M.; Doostmohammadi, H.; Raiszadeh, R. Effect of Si and Al on the microstructure, mechanical properties and machinability of 65Cu-35Zn brass. Iran. J. Mater. Sci. Eng. 2019, 16, 21-32. 
5. Sohn, S.; Kang, T. The effects of tin and nickel on the corrosion behavior of 60Cu-40Zn alloys. J. Alloy. Comp. 2002, 335, 281-289. [CrossRef]

6. Bydalek, A.W.; Kula, A.; Blaz, L.; Najman, K. Analysis of the impact of modifiers on the formation of non-metallic inclusions during continuous casting of CuZn39Pb2 brass. Arch. Foundry Eng. 2019, 19, 21-26.

7. Suárez, L.; Rodriguez-Calvillo, P.; Cabrera, J.M.; Martinez-Romay, A.; Majuelos-Mallorquin, D.; Coma, A. Hot working analysis of a $\mathrm{CuZn} 40 \mathrm{~Pb} 2$ brass on the monophasic $(\beta)$ and intercritical $(\alpha+\beta)$ regions. Mater. Sci. Eng. A 2015, 627, 42-50. [CrossRef]

8. Chen, W.; Jia, Y.; Yi, J.; Wang, M.; Derby, Q.; Lei, B. Effect of addition of Ni and Si on the microstructure and mechanical properties of Cu-Zn alloys. J. Mater. Res. 2017, 32, 3137-3145. [CrossRef]

9. Suksongkrm, P.; Rojananan, S.; Rojananan, S. Bismuth formation in lead-free Cu-Zn-Si yellow brass with various bismuth-tin alloy additions. Mater. Trans. 2018, 59, 1747-1752. [CrossRef]

10. Humphreys, F.J.; Hatherly, M. Chapter 13 hot deformation and dynamic restoration. In Recrystallization and Related Annealing Phenomena; Elsevier: Pittsburgh, PA, USA, 2004.

11. McQueen, H.J.; Imbert, C.A.C. Dynamic recrystallization: Plasticity enhancing structural development. J. Alloy. Comp. 2004, 378, 35-43. [CrossRef]

12. Zhang, Y.; Guo, J.M.; Chen, J.H.; Wu, C.L.; Kormout, K.S.; Ghosh, P.; Zhang, Z.L. On the stacking fault energy related deformation mechanism of nanocrystalline $\mathrm{Cu}$ and $\mathrm{Cu}$ alloys: A first-principles and TEM study. J. Alloy. Comp. 2019, 776, 807-818. [CrossRef]

13. Spigarelli, S.; Mehtedi, M.E.; Cabibbo, M.; Gabrielli, F.; Ciccarelli, D. High temperature processing of brass: Constitutive analysis of hot working of Cu-Zn alloys. Mater. Sci. Eng. A 2014, 615, 331-339. [CrossRef]

14. Ashby, M.F.; Gandhi, C.; Taplin, D.M.R. Perspectives in Creep Fracture; Elsevier: Cambridge, UK, 1983; pp. 1-31.

15. Wolley, D.J.; Fox, A.G. The embrittlement of leaded and unleaded $\alpha+\beta(60-40)$ brasses in the temperature range 300 to $500{ }^{\circ}$ C. J. Mater. Sci. Lett. 1988, 7, 763-765. [CrossRef]

16. Heidersbach, R.H.; Verink, E.D. The dezincification of alpha and beta brasses. Corrosion 1972, 28, $397-418$. [CrossRef]

17. Park, C.G.; Kim, J.G.; Chung, Y.M.; Han, J.G.; Ahn, S.H.; Lee, C.H. A study on corrosion characterization of plasma oxidized 65/35 brass with various frequencies. Surf. Coat. Tech. 2005, 200,77-82. [CrossRef]

18. Illarionov, A.G.; Loginov, Y.N.; Stepanov, S.I.; Illarionova, S.M.; Radaev, P.S. Variation of the structure-and-phase condition and physical and mechanical properties of cold-deformed leaded brass under heating. Met. Sci. Heat Treat. 2019, 61, 243-248. [CrossRef]

19. Chu, Z.K.; Yu, J.J.; Sun, X.F.; Guan, H.R.; Hu, Z.Q. Tensile property and deformation behavior of a directionally solidified Ni-base superalloy. Mater. Sci. Eng. A 2010, 527, 3010-3014. [CrossRef]

20. Izumi, O. Intermediate temperature embrittlement and intercrystalline cracking in copper alloys. Bull. J. Jpn. Inst. Met. 1979, 54, 15-22. [CrossRef]

21. Giacobbe, F.W. Thermodynamic dezincification behavior of brass during annealing. J. Alloy. Comp. 1993, 202, 243-250. [CrossRef]

(C) 2020 by the author. Licensee MDPI, Basel, Switzerland. This article is an open access article distributed under the terms and conditions of the Creative Commons Attribution (CC BY) license (http://creativecommons.org/licenses/by/4.0/). 